\title{
CARACTERIZAÇÃO MAGNETO-ÓPTICA DE AÇO INOXIDÁVEL AUSTENÍTICO DEFORMADO A FRIO*
}

\author{
Lucas Kling e Silva \\ Vitor Manoel de Araújo Silva² \\ Clara Johanna Pacheco ${ }^{3}$ \\ Gabriela Ribeiro Pereira ${ }^{4}$
}

\section{Resumo}

Os aços inoxidáveis são materiais utilizados em ramos da indústria que demandam além de boa resistência à corrosão, elevada resistência mecânica. As ligas inoxidáveis austeníticas geralmente são submetidas ao trabalho a frio visando seu endurecimento, uma vez que não são endurecíveis via tratamento térmico. Devido à deformação plástica, pode ocorrer a transformação da austenita em martensita para algumas classes de aços. Esta transformação, dependendo da fração de fase transformada pode levar à redução da tenacidade. O foco deste trabalho está, portanto, na identificação e quantificação da martensita em amostras deformadas. Para isto, corpos de prova de aço austenítico AISI 321 foram deformados mediante laminação a frio e caracterizados pelo magnetômetro de amostra vibrante (VSM) e pela técnica Bitter modificada ao ferrofluido. Os resultados exibiram a fácil formação de martensita no aço e uma abordagem muito eficaz para revelar esta fase nas imagens de microscopia ótica. Com os valores de saturação magnética provenientes do VSM foi possível estimar a fração volumétrica da martensita para cada condição de deformação.

Palavras-chave: Aços inoxidáveis; Ferrofluido; Laminação; Transformação martensítica.

\section{MAGNETO-OPTIC CHARACTERIZATION FOR AUSTENITIC STAINLESS STEEL AFTER COLD WORK}

\section{Abstract}

Stainless steels are materials used in many industry sectors that require good corrosion resistance as well as high mechanical strength. The austenitic stainless steels usually are submitted to cold working steps, in order to harden the material, since they are not hardened by heat treatment. Because of the plastic deformation, it may occur microestructural transformations from austenite to martensite in some classes of steels. Such transformations can lead to loss of thoughness depending on the fraction of the transformed phase. The purpose of this study relies on the identification and quantification of the martensite present in deformed samples. To make it possible, some samples of an austenitic steel AISI 321 were deformed through cold rolling and characterized by the Vibrating Sample Magnetometer (VSM) and the Bitter ferrofluid modified technique. The results exhibited an easy formation of martensite in the steel and an effective approach to reveal that phase in the optical microscopy. With the magnetic saturation values obtained from the VSM it was possible to estimate the volumetric fraction of martensite for each deformation condition.

Keywords: Stainless steels; Ferrofluid; Rolling; Martensitic transformation.

1 Graduando em Engenharia Metalúrgica, Departamento de Engenharia Metalúrgica e Materiais, Universidade federal do Rio de Janeiro - UFRJ, Rio de Janeiro, RJ, Brasil.

2 Doutorando em Engenharia de Materiais, Mestre, pesquisador, Laboratório de Ensaios Não Destrutivos, Corrosão e Soldagem - LNDC, Rio de Janeiro, RJ, Brasil

3 Doutora em Física, pesquisadora, Laboratório de Ensaios Não Destrutivos, Corrosão e Soldagem LNDC, Rio de Janeiro, RJ, Brasil.

4 Doutora em Engenharia Nuclear, Doutora, coordenadora da área de ensaios não destrutivos, Laboratório de Ensaios Não Destrutivos, Corrosão e Soldagem - LNDC, Rio de Janeiro, RJ, Brasil. 


\section{INTRODUÇÃO}

Aços inoxidáveis austeníticos apresentam certas características, que os tornam de interesse na indústria como: elevada resistência à corrosão em diversos meios, boa tenacidade em temperaturas baixas e excelente capacidade de conformação [1]. No entanto, uma de suas limitações é o baixo limite de escoamento no estado recozido. Para solução deste problema, existem alguns mecanismos disponíveis, dos quais podem ser destacados o refino de grão, a manipulação da composição química e a deformação a frio, sendo desprezado o tratamento térmico já que estas ligas não são endurecíveis por precipitação [2].

O endurecimento dos aços austeníticos por trabalho a frio está baseado tanto na geração e interação das discordâncias como na transformação da fase austenítica em martensita [3]. No papel de fase endurecedora, a martensita promove o aumento da resistência mecânica como desejado, porém, dependendo da quantidade presente, o material pode experimentar uma queda significativa na tenacidade, sendo em alguns casos um problema. Alguns pesquisadores observaram através da difração de raios $X$ que a transformação martensítica ocasionada pelo trabalho a frio gera tanto martensita $\varepsilon, \mathrm{HC}$ e paramagnética, quanto martensita $\alpha$ ', $\mathrm{CCC}$ e ferromagnética, sendo esta última a forma presente em deformações acima de 10\% [4]. Assim, torna-se viável a aplicação de técnicas que explorem as propriedades magnéticas das fases para caracterização do material e seu grau de deformação. Para tal, este trabalho empregou a técnica de magnetômetria e a técnica Bitter modificada ao ferrofluido, que é classificado como um ataque magnético.

\subsection{Magnetômetro de amostra vibrante (VSM)}

Este equipamento é utilizado para avaliar as propriedades magnéticas dos materiais, como magnetização e permeabilidade magnética [4]. Para realização do teste, a amostra é fixada em uma haste que está presa a uma cabeça vibratória e faz a amostra vibrar a uma frequência fixa. Em seguida, um campo magnético perpendicular à direção da haste é gerado pelas bobinas de um eletroímã. $\mathrm{Na}$ amostra que permanece vibrando, são geradas correntes induzidas bem como um campo magnético induzido que é detectado por bobinas coletoras, o que induz uma voltagem. A partir da medida da voltagem com as bobinas coletoras as informações sobre as propriedades magnéticas podem ser adquiridas [5] [6].

\subsection{Técnica Bitter modificada com ferrofluido}

Esta técnica consiste no recobrimento de uma amostra ferromagnética com uma solução coloidal que contêm partículas superparamagnéticas. Estas partículas tenderão a se concentrar nas regiões de maior informação magnética.

O ferrofluido é uma solução coloidal de partículas superparamagnéticas na escala nanométrica. Este fluido reage mesmo a ínfimos campos magnéticos, de forma que suas partículas reagem ao campo magnético proveniente das fases ferromagnéticas, aglomerando-se nestas regiões, sem modificar sua magnetização natural [7].

\section{MATERIAIS E MÉTODOS}

Utilizou-se uma chapa de aço inoxidável austenítico AISI 321 laminada e recozida, com dimensões iniciais de $500 \mathrm{~mm} \times 145 \mathrm{~mm} \times$ 9,5 mm. A composição química deste 
aço está presente na Tabela 1 e foi obtida a partir do certificado fornecido pelo fabricante.

Tabela 1: Composição química do aço. Valores de porcentagem em peso (\%).

\begin{tabular}{|c|c|c|c|c|c|c|}
\hline & $\mathrm{C}$ & $\mathrm{Mn}$ & $\mathrm{Si}$ & $\mathrm{P}$ & $\mathrm{S}$ & $\mathrm{Cr}$ \\
\cline { 2 - 7 } Aço AISI \\
321 & 0,009 & 0,820 & 0,480 & 0,036 & 0,002 & 17,050 \\
\cline { 2 - 7 } & $\mathrm{Ni}$ & $\mathrm{Mo}$ & $\mathrm{Al}$ & $\mathrm{Cu}$ & $\mathrm{N}$ & $\mathrm{Ti}$ \\
\cline { 2 - 7 } & 9,040 & 0,038 & 0,006 & 0,054 & 0,009 & 0,122 \\
\hline
\end{tabular}

A partir da chapa foram cortadas quatro amostras as quais foram submetidas ao processo de solubilização à $1100^{\circ} \mathrm{C}$ por 30 minutos, com posterior resfriamento em água à temperatura ambiente. Finalmente, foram lixadas com intuito de retirar a camada de óxido formada durante o tratamento térmico.

\subsection{Deformação a frio}

O processo de deformação ocorreu com a laminação em temperatura ambiente, onde, após cada passe, as amostras foram resfriadas em água. Foi utilizado um laminador FENN do tipo duo reversível com cilindros de $135 \mathrm{~mm}$ de diâmetro e velocidade de rotação de 30 RPM. Após cada passe, a espessura das amostras foi medida com um paquímetro em três pontos distintos e a média considerada como a espessura final de cada passe.

As deformações verdadeiras utilizadas neste estudo foram de 0,00 dv, 0,27 dv, 0,55 dv e 2,94 dv. Para o cálculo da espessura final que resultaria no nível de deformação desejado, foi utilizada a Equação (1).

$$
t f=e^{d v} \cdot t i
$$

Onde dv é a deformação verdadeira na direção da espessura (adimensional), tf é espessura final $(\mathrm{mm})$ e ti é espessura inicial ( $\mathrm{mm})$.

Vale destacar que as deformações foram realizadas dentro de uma série de passes de laminação, com cada um deles sendo capaz de reduzir a espessura em apenas $0,1 \mathrm{~mm}$.

\subsection{Microscopia ótica}

Para a análise no microscópio ótico, foram retiradas amostras através de corte com disco diamantado em baixa rotação. A face preparada para observação foi referente à espessura, estando a laminação na direção horizontal das imagens. Após o lixamento e polimento mecânico, o ataque foi realizado em duas etapas: a primeira com ataque eletrolítico a fim de revelar contornos de grão. Em seguida, com o ferrofluido, para visualizar a martensita $\alpha$ '. Após a primeira etapa do ataque foram obtidas imagens, bem como após a aplicação do ferrofluido. Os reagentes utilizados e suas características podem ser conferidos na Tabela 2. 
Tabela 2: Reagentes utilizados para o ataque.

\begin{tabular}{|c|c|c|}
\hline Ataque & Reagente & Caracterísiticas \\
\hline Eletrolítico & $\mathrm{HNO}_{3} 60 \%$ & Tensão: $1,5 \mathrm{~V} /$ Tempo: 30s \\
\hline Magnético & EMG 911 Diluição (1:60) & Tempo: $20 \mathrm{~min}$ \\
\hline
\end{tabular}

\subsection{Magnetômetro de amostra vibrante (VSM)}

O equipamento utilizado para realização das medidas foi o LakeShore $\AA$ modelo EM4 - HV com um campo magnético aplicado $(H)$ variando entre 0 e 17000 Gauss. Em função do campo aplicado, foram obtidos os valores de magnetização (M) para cada amostra e após a medida da massa de cada uma, obtida a magnetização em emu/g. É válido destacar ainda que as amostras para este ensaio foram cortadas através do processo de eletroerosão a fio, no formato de cilindros com 3,0mm de diâmetro por 2,6 $\mathrm{mm}$ de altura.

No gráfico da magnetização em função do campo aplicado, obteve-se a magnetização de saturação para cada deformação e, de acordo com a Equação (2) foi possível estimar a fração volumétrica da martensita em cada condição de deformação.

$$
C_{\alpha \prime}=\frac{m_{s}}{m_{s i}}
$$

Onde $C_{\alpha^{\prime}}$ é a fração de martensita $\alpha^{\prime}, m_{s}$ a magnetização de saturação em cada condição de deformação e $m_{\mathrm{si}}$ a magnetização de saturação intrínseca da martensita. $\mathrm{O}$ método proposto para achar tanto $\mathrm{m}_{\mathrm{s}}$ como $\mathrm{m}_{\mathrm{si}}$ foi o mesmo utilizado por outros pesquisadores [8], que consiste em ajustar uma reta nos pontos que estão entre $90 \%$ e $100 \%$ do campo aplicado. A interseção da reta com o eixo das ordenadas consistirá no valor de magnetização de saturação.

\section{RESULTADOS E DISCUSSÃO}

A seguir serão apresentados os resultados obtidos através da microscopia ótica bem como aqueles referentes ao magnetômetro de amostra vibrante (VSM).

\subsection{Microscopia ótica}

A Figura 1 mostra a microestrutura do aço que não sofreu deformação e passou apenas pela etapa de ataque com o ácido nítrico. Observam-se contornos delimitando grãos austeníticos equiaxiais. Além dos grãos, nota-se também estrias na direção horizontal da imagem. Como esta amostra foi solubilizada e não passou por deformação, é possível que estas linhas sejam provenientes de processos anteriores à sua aquisição, ainda na fabricação. Apesar do aço inoxidável austenítico geralmente apresentar maclas de recozimento em sua microsestrutura, o ataque com ácido nítrico não tem o objetivo de revelá-las, por isso não aparecem na imagem. 


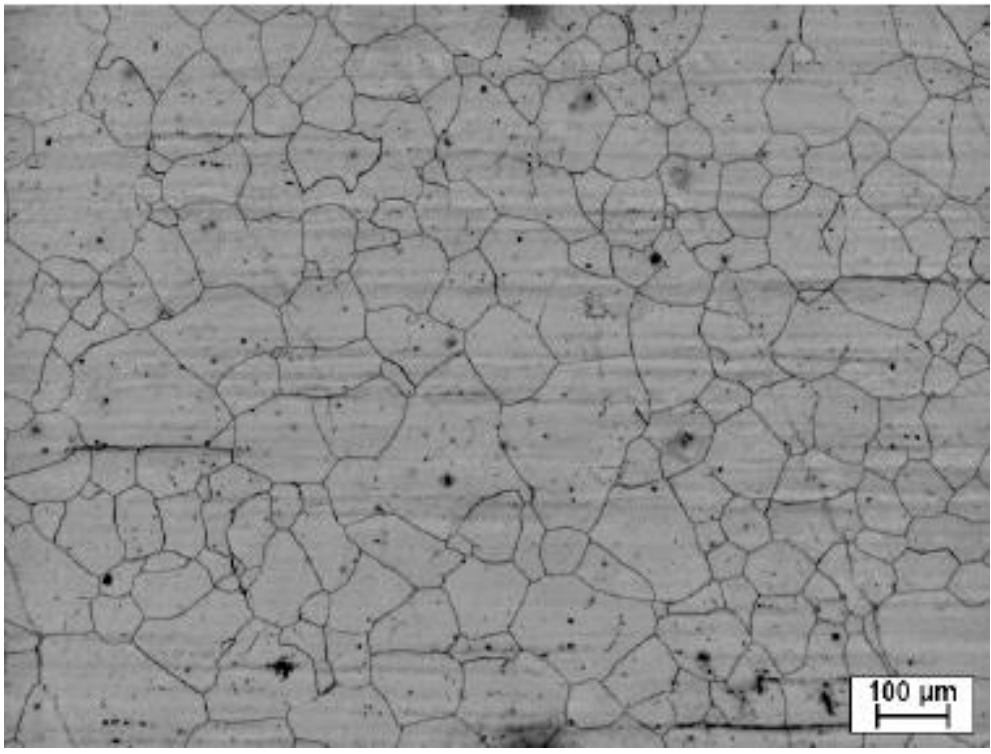

Figura 1. Amostra sem deformação. Ataque com ácido nítrico.

A imagem seguinte, Figura 2, corresponde à mesma amostra que a anterior. No entanto, esta foi atacada não só com o ácido nítrico mas também com o ferrofluido. $\mathrm{Na}$ imagem, além das estrias, percebe-se a presença de agulhas mais escuras, que correspondem à martensita $\alpha$ '. Elas são mais escuras que a fase austenítica pois as partículas do ferrofluido se aglomeram nestes locais e espalham a luz que incide sobre a amostra. É possível afirmar que as regiões escuras são constituídas de martensita $\alpha^{\prime}$ pois este é o único microconstituinte que tem comportamento magnético.

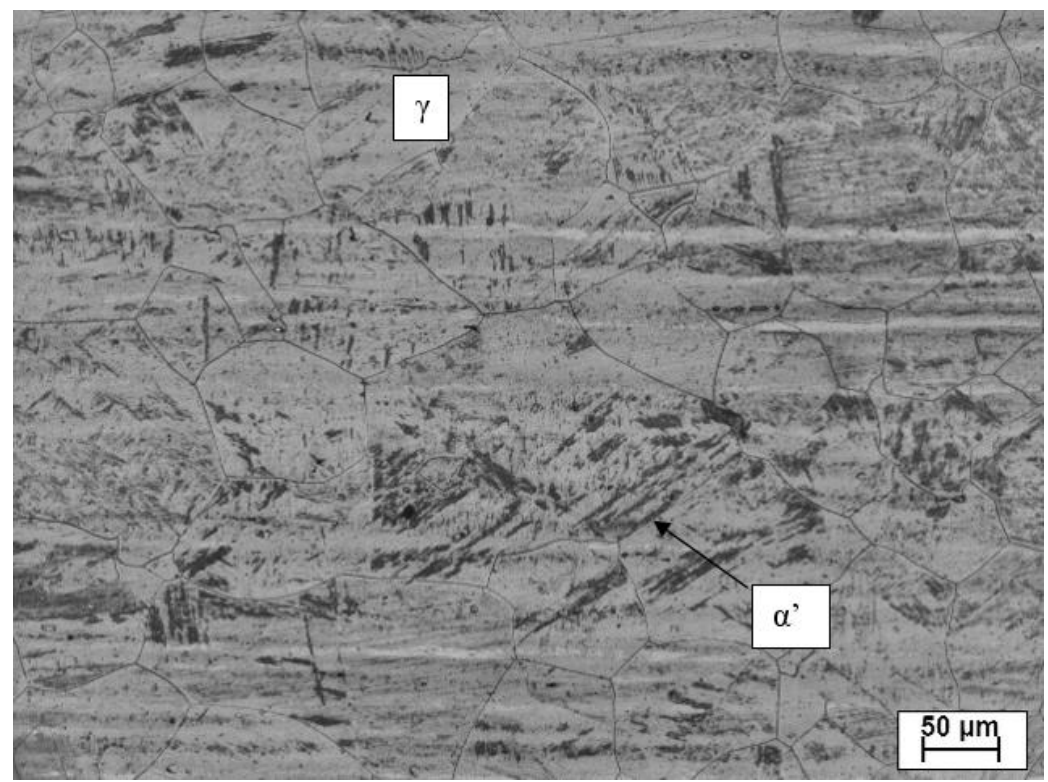

Figura 2. Amostra sem deformação. Ataque com ácido nítrico e ferrofluido.

Em seguida, a Figura 3 mostra a micrografia da amostra que foi deformada ao nível de $0,27 \mathrm{dv}$. Observa-se além dos contornos de grão da austenita prévia, as ripas paralelas de martensita. A martensita dispõe-se de maneira paralela umas às outras pois forma-se na interseção das bandas de cisalhamento, como reportou [9]. 


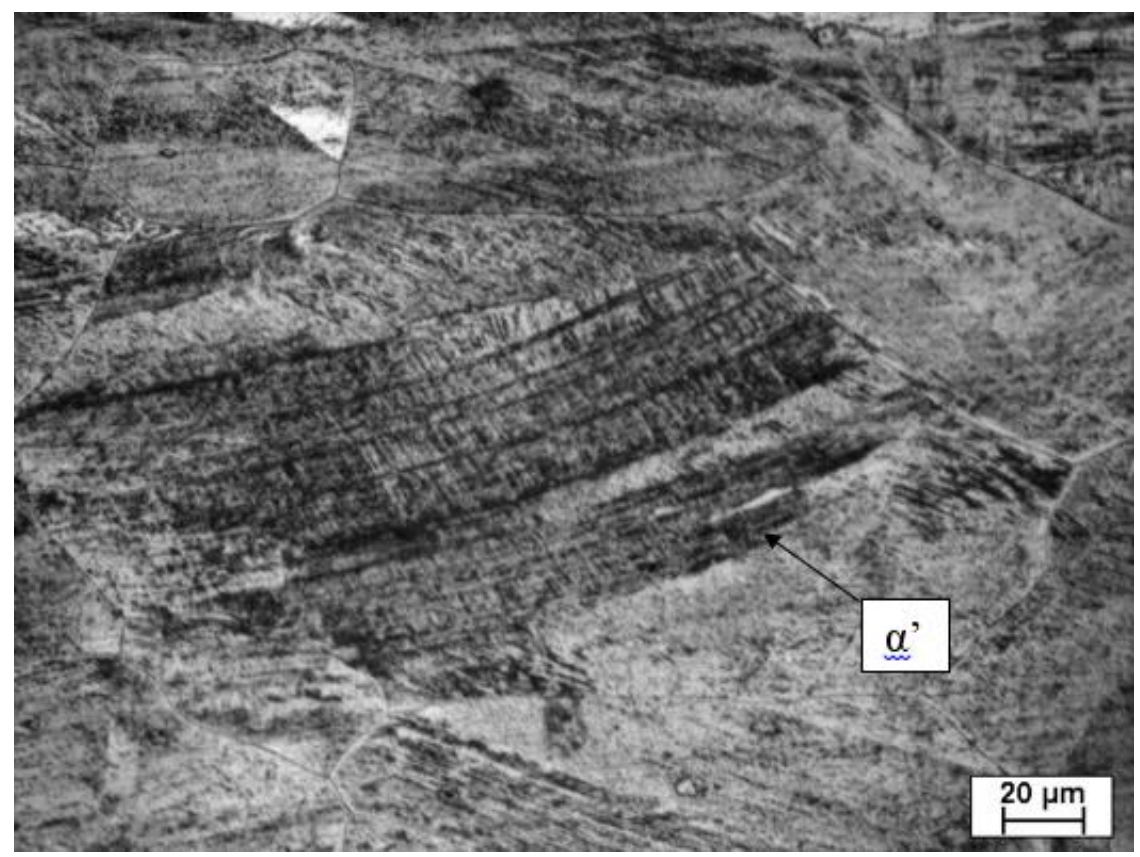

Figura 3. Amostra com 0,27 dv. Ataque com ácido nítrico e ferrofluido.

A Figura 4 refere-se à amostra com $0,55 d v$. Ao comparar com a imagem da Figura 3 (mesmo aumento, porém com deformação menor, de 0,27 dv) nota-se o grão mais alongado, resultado da maior deformação imposta. Outrossim, a martensita deixa de se apresentar no formato de ripas paralelas, adquirindo um formato mais curvo. Isto ocorre porque a transformação martensítica acompanha o avanço da banda de cisalhamento, a qual assume uma curvatura à medida prossegue pelo grão austenítico [10].

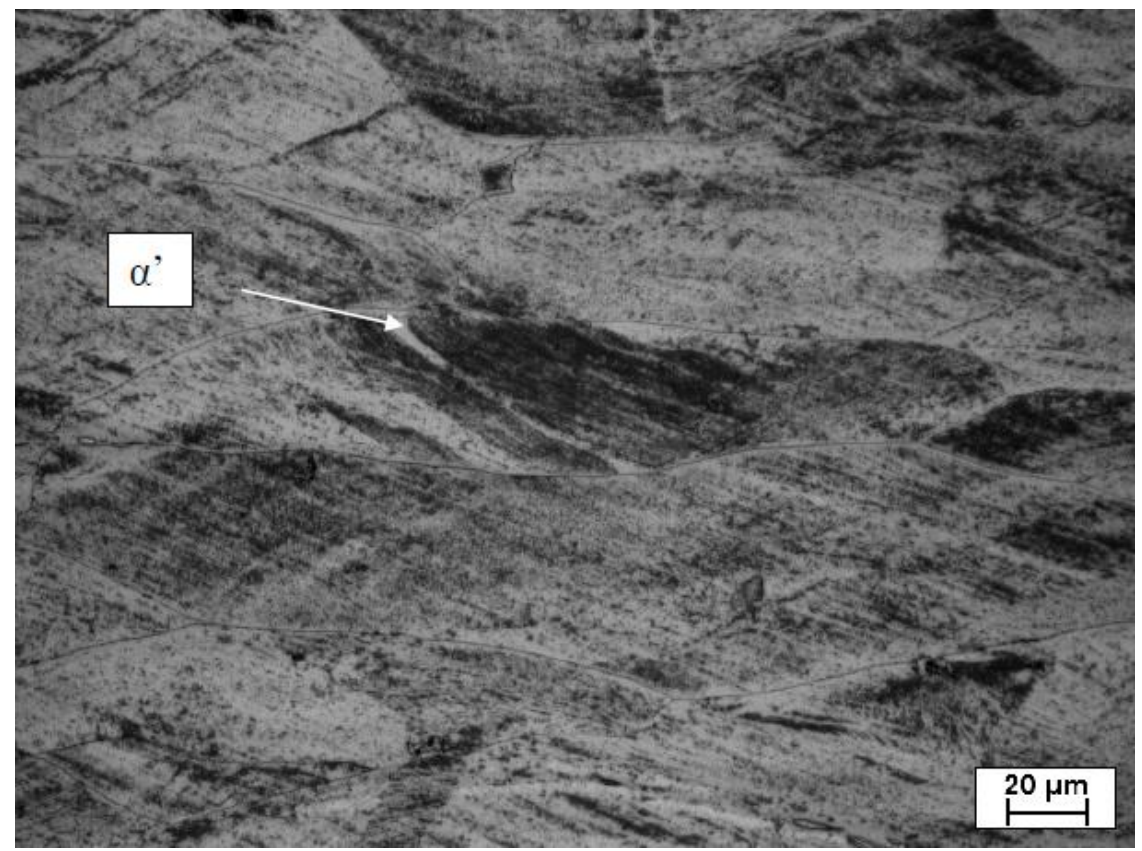

Figura 4. Amostra com 0,55 dv. Ataque com ácido nítrico e ferrofluido. 
Observando as imagens anteriores, cabe destacar o benefício do ataque com ácido nítrico em conjunto com o ferrofluido. Primeiramente, o ácido nítrico é ideal para a revelação de grãos austeníticos e o ferrofluido se mostrou útil na detecção da fase ferromagnética (martensita $\alpha^{\prime}$ ). Mesmo à deformação elevada, como 0,55 dv, através destes dois ataques foi possível distinguir contornos de grãos das regiões onde há $\alpha$ '. Isto não é possível quando se utiliza como ataque apenas o ácido oxálico, recomendado na norma E407-99 [11], conforme alguns pesquisadores realizaram [12]. Nota-se que na deformação em torno de $0,55 \mathrm{dv}$ o ácido oxálico ataca a martensita e os contornos de grão de maneira indistinta, não permitindo a separação destas regiões.

\subsection{Magnetômetro de amostra vibrante (VSM)}

O gráfico a seguir, presente na Figura 5, é referente às curvas obtidas no VSM, de onde foi possível obter a magnetização de saturação de cada condição de deformação. Nas curvas de magnetização, destaca-se primeiramente a amostra com deformação nula $(0,00 \mathrm{dv})$ que apresenta um comportamento linear entre a magnetização e o campo magnético aplicado e com valores de magnetização inferiores a $1 \mathrm{emu} / \mathrm{g}$, resposta associada a materiais paramagnéticos. Já a curva de magnetização para a amostra com deformação de $0,27 \mathrm{dv}$, pode-se observar que o valor da magnetização aumenta conforme é incrementado o campo magnético aplicado. Para esta amostra foi atingido um valor de saturação entorno de $90 \mathrm{emu} / \mathrm{g}$. A magnetização existente pode ser atribuída à presença de fases ferromagnéticas no material. Isto demonstra que houve formação de martensita a' por conta da deformação imposta. Apresentando comportamento análogo, a amostra com 0,55 dv é magnetizada em função do campo magnético externo, possuindo um patamar de magnetização maior que o da amostra com $0,27 \mathrm{dv}$. Finalmente, o gráfico mostra a curva para uma deformação de $2,94 \mathrm{dv}$. Nesta deformação, o material teve sua microestrutura completamente transformada de austenita em martensita. Isto foi confirmado através da difração de raios X [8] além da comparação com trabalhos que estudaram aços da mesma classe [8]. Nesta condição a amostra indica que é magnetizada mais rapidamente em relação as amostras com menor grau de deformação, conseguindo valores de saturação entorno de $130 \mathrm{emu} / \mathrm{g}$, que é a magnetização intrínseca da martensita. 


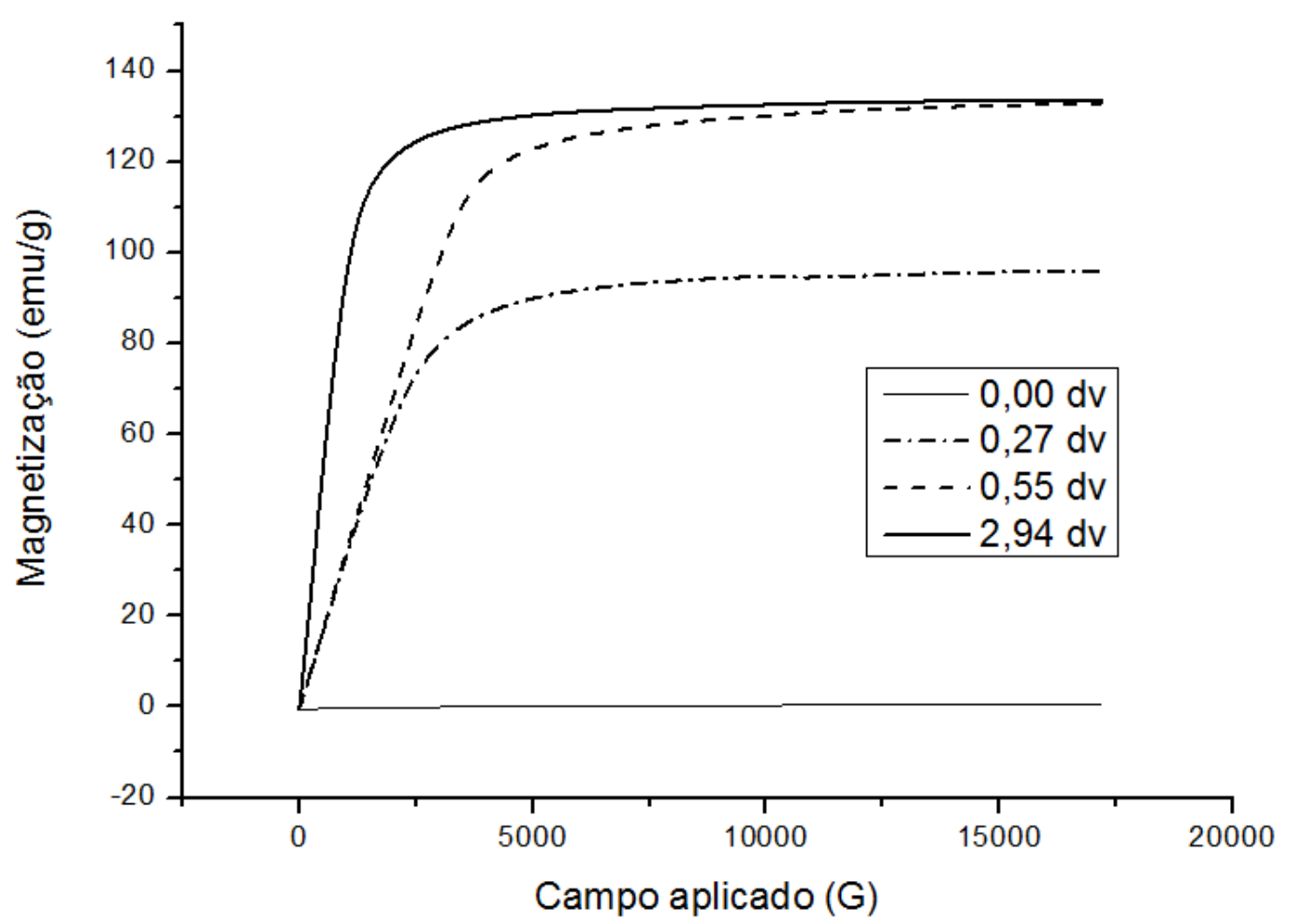

Figura 5. Curvas de magnetização.

$\mathrm{Na}$ Tabela 3 está um resumo da magnetização de saturação das condições analisadas, além da magnetização intrínseca da martensita. Além disso, a fração volumétrica de martensita obtida através da Equação 2.

Tabela 3: Magnetização de saturação e fração de martensita nas amostras com diferentes deformações.

\begin{tabular}{|c|c|c|c|}
\hline Condição & $\begin{array}{c}\text { Magnetização de } \\
\text { saturação }\left(\mathrm{m}_{\mathrm{s}}\right) \\
(\mathrm{emu} / \mathrm{g})\end{array}$ & $\begin{array}{c}\text { Magnetização de } \\
\text { saturação } \\
\text { intrínseca }\left(\mathrm{m}_{\mathrm{si}}\right)\end{array}$ & $\begin{array}{c}\text { Fração de } \\
(\mathrm{emu} / \mathrm{g})\end{array}$ \\
\hline $0,00 \mathrm{dv}$ & 0,02 & & \\
martensita $\left(\mathrm{C}_{\alpha^{\prime}}\right)$
\end{tabular}

Apesar dos resultados de microscopia ótica terem revelado a formação de martensita na amostra com 0,00 dv, é possível afirmar que limitou-se apenas à superfície da amostra, uma vez que o VSM não revelou magnetização significativa desta condição, resultando em uma fração de $\alpha^{\prime}$ igual a zero.

Já as amotras de 0,27dv e 0,55 dv, que demonstraram presença de martensita na microscopia ótica, exibiram magnetizações apreciáveis no ensaio com o VSM. Isto, permite determinar que a transformação martensítica não limitou-se apenas à superfície da amostra, mas se deu também ao longo da espessura do material. 


\section{CONCLUSÃO}

De acordo com o estudo realizado pode-se destacar que:

- A ocorrência de martensita a' na amostra sem deformação $(0,00 \mathrm{dv})$ indica que a martensita no aço AISI 321 com baixo carbono forma-se facilmente, mesmo com o lixamento. Esta martensita limitou-se à superfície do material uma vez que, nos resultados do $V S M$, a magnetização desta amostra é próxima de zero. Já as outras amostras, com diferente grau de deformação, apresentaram magnetização apreciável sendo possível estimar a fração de martensita presente.

- Com a aplicação do ferrofluido, é possível garantir que apenas a martensita a' está sendo revelada, uma vez que esta é a única fase magnética presente. Quando aplicado posteriormente ao ácido nítrico, é uma abordagem eficaz para revelar na mesma imagem tanto martensita quanto contornos de grão, mesmo a elevadas deformações. Isto não é possível ao utilizar-se o ataque tradicional, com o ácido oxálico.

\section{Agradecimentos}

Os autores agradecem à Capes e ao CNPQ pelo apoio financeiro.

\section{REFERÊNCIAS}

1 Krauss, G., Steels: Processing, Structure and Performance. 1 $1^{\mathrm{a}}$ ed. Ohio, ASM International, 2003; COSTA e SILVA et al., 2006

2 Dieter, G.E. Mechanical Metallurgy. International Student Edition, New York, McGrawHill, 1961.

3 Totten, G. E., Steel Heat Treatment - Metallurgy and Technologies. $2^{\mathrm{a}}$ Ed., Florida, CRC Press, 2007.

4 Abreu, H. F. G., CARVALHO, S. S., NETO, P. L., et al. "Deformation Induced Martensite in an AISI 301LN Stainless Steel: Characterization and Influence on Pitting Corrosion Resistance". Materials Research v. 10, n. 4, pp. 359-366, Nov, 2007.

5 Jiles, D. Introduction to Magnetism and Magnetic Materials. $2^{\stackrel{a}{ }}$ ed., New York, Chapman \& Hall, 1998.

6 Foner, S. "Versatile and Sensitive Vibrating-Sample Magnetometer". Review of Scientific Instruments v. 30, pp. 548-557, 1959.

7 Silva, L.K., 2015. Caracterização Magnética dos Efeitos de Deformação em Aços Ferríticos Através da Técnica Bitter Modificada. Projeto de Graduação, DEMM/ UFRJ, Rio de Janeiro, RJ, Brasil.

8 Pardal, J.M., MONTENEGRO, T.R., TAVARES, M.T., et al. "Avaliação da Transformação Martensítica Induzida por Deformação a Frio no Aço Inoxidável AISI 321 de Baixo Teor de Carbono". XI Seminário Brasileiro do Aço Inoxidável, São Paulo, Outubro, 2012.

9 Talonen, J., hänninen, H. "Formation of Shear Bands and Strain-Induced Martensite During Plastic Deformation of Metastable Austenitic Stainless Steels". Acta Materialia v .55, n. 18, pp $6108-6118,2007$.

10 Lichtenfeld, J.A., MATAYA, M.C., VAN TYNE, C.J. "Effect of Strain Rate on StressStrain Behavior of Alloy 309 and 304L Austenitic Stainless Steel". Metallurgical and Materials Transations A v. 37A, pp 147-161, Jan, 2006.

11 ASTM E407-99, Standard Practice for Microetching Metals and Alloys

12 Hedayati, A., NAJAFIZADEH, A., KERMANPUR, A., et al. "The Effect of Cold Rolling Regime on Microstructure and Mechanical Properties of AISI 304L Stainless Steel". Journal of Materials Processing Technology v. 210, pp. 1017-1022, Feb., 2010. 